\title{
EARLY POST-OPERATIVE DETACHMENT OF THE CHOROID*
}

BT

Francis Csillag

-

BUDAPEST

EARLY post-operative detachment is a secondary and long known phenomenon. It occurs as an unexpected sequence after cataract. glaucoma, iridectomy, trephine, sclerectomy and cyclodialysis operations. Its incidence, according to the various authors, varies much. The highest percentage is reported by O'Brien, who states that 62 per cent. of his operations were immediately followed by detachment of the choroid.

Origin of the detachment is. explained differently by various authors. Fuchs assumes a warping of the choroid, while Meller and O'Brien believe an imperfect healing of the incision to be responsible. Meesmann, Hagen, Urbanek and Fronimopoulos think the post-operative hypotony to be of significance. Lindner is of the opinion that the contracting vitreous body exerts traction on the choroid. Bonnet and Grandclement assume a relationship with existing general or ophthalmological disease. A considerable number of the authors think that behind the detached choroid, blood (Urbanek) or fluid accumulates, but they differ concerning the origin and the active or passive consequences of the same. A transudate from the choroidal vessels is assumed by Hagen, O'Brien, Fronimopoulos and Meesmann, whereas Meller thinks that the ciliary body forms the liquid. H. D. Mayer (1939) states that the aqueous oozing backwards through the loosened attachment of the ciliary body forces the choroid off its base. The cause of hypotony is the increaséd outflow of the aqueous. If the anterior chamber is well preserved and pressure remains normal, she believes serous exudation. to be of importance.

Csillag has emphasized in his lecture (delivered at the Hungarian Ophthalmological Society, 1939), that if during operation a communication is established between the anterior chamber and the supra-choroidal space, the aqueous oozes backwards and detaches the choroid. The increased outflow of the aqueous causes a shallow chamber to form and hypotony to ensue. His lecture has been published late, owing to war-time difficulties.

The choroid adheres to its base only at the head of the optic nerve and where the veins perforate the sclera. The operative deformation of the eye-ball may cause the choroid to become loose and warp at its base (commotio of the choroid). The decrease of

* Received for publication April 11, 1949 
pressure may permit transudate from the vessels to enter the suprachoroidal space, gently elevating the choroid (amotio of the choroid). Such a detachment is small and flat, and the fluid behind it is of insignificant amount (O'Brien's frequent detachments seem to have been of this kind). Such detachments should not be regarded as being genuine ones (ablations), as, following reunion of the lips of the incision and re-establishment of intra-ocular pressure, they tend to disappear.

Three different methods of cataract extraction were used at the ophthalmic clinic of Budapest University at a certain time. The origin of the choroidal detachment depended, as the author was able to ascertain, chiefly on the method of incision and partly on that of extraction. The least number of detachments followed incision which was conducted entirely within the limbus (conjunctival apron); they became more frequent following the conjunctival flap method (the incision can be finished sclerally in that case), and the most frequent detachments occurred, despite correct operation and uneventful healing, following Horváth's scleral flap method. Intracapsular extraction and subsequent extraction of the capsule increased the incidence of detachment.

This incidence is demonstrated by the following table :

\begin{tabular}{|c|c|c|c|c|c|c|c|c|c|}
\hline \multirow{2}{*}{$\begin{array}{l}\text { Method of incision } \\
\text { Conjunctival apron } \\
\text { Conjunctival flap } \\
\text { Scleral flap ... }\end{array}$} & \multicolumn{3}{|c|}{\begin{tabular}{|c|c|} 
Intracapsular \\
extract. \\
$\begin{array}{c}\text { detachm. } \\
\text { per cent. }\end{array}$
\end{tabular}} & \multicolumn{3}{|c|}{\begin{tabular}{c|c}
\multicolumn{2}{c}{ Extracapsular } \\
extract. & $\begin{array}{c}\text { detachm. } \\
\text { per cent }\end{array}$
\end{tabular}} & \multicolumn{3}{|c|}{ extract. $\mid \begin{array}{c}\text { Total } \\
\text { detachm. } \\
\text { per cent. }\end{array}$} \\
\hline & $\begin{array}{r}279 \\
79 \\
334\end{array}$ & $\begin{array}{r}2 \\
2 \\
14\end{array}$ & $\begin{array}{l}0.72 \\
2.53 \\
4.19\end{array}$ & $\begin{array}{r}136 \\
74 \\
193\end{array}$ & $\begin{array}{l}1 \\
1 \\
4\end{array}$ & $\begin{array}{l}0.73 \\
1.35 \\
2.07\end{array}$ & $\begin{array}{l}415 \\
153 \\
527\end{array}$ & $\begin{array}{r}3 \\
3 \\
18\end{array}$ & $\begin{array}{l}0.70 \\
1.96 \\
3.41\end{array}$ \\
\hline Total & 692 & 18 & 2.60 & 403 & 6 & 1.48 & 1095 & 24 & 2.19 \\
\hline
\end{tabular}

Only those cases were investigated for detachment which were conspicuously late in re-filling the chamber. Thus only those cases remained undetected, which required 2 to 3 days in re-establishing the chamber and the detached part was replaced on the 6 th to 7 th day at a time, when it became possible to examine the eye with a mirror. Therefore we may assume this post-operative complication to be more frequent than is shown in the table above. But all sorts of incision may react likewise and therefore the relative probability and conclusions drawn therefrom remain the same.

Detachment more frequently occurs after complete iridectomy and following basal iridectomy, but there is no considerable difference. Various iris operations have not been included in the table, not being of decisive influence concerning detachment. The extraction has been regarded as being intracapsular when the lens was removed 
together with an intact capsule. I believe it is unlikely that detachment is influenced by age, sex, ocular alteration or systemic disease.

After cataract extraction the intra-ocular pressure decreases, the vessels of the choroid dilate and gently push the vitreous body forward. As soon as the wound closes, the accumulated aqueous refills the vitreous body and the deep chamber, which characterizes aphakia. The physiological equilibrium between loss and production of aqueous re-establishes itself, and intra-ocular pressure stabilizes. The patients were not examined by a retinoscope on the days immediately following operation. Perhaps this circumstance accounts for the fact that detachments were less frequently noted by us than by other authors, and none of the aforesaid flat detachments called "amotio" occurred. The onset of detachment is shown by the chamber remaining flat for days, and by hypotony. The detachments began in the upper half (or were drawn up there), and proceeded from there downward and backward. Even simple illumination discloses the dark-grey object bulging into the vitreous body, situated next to the ciliary body, which can be trans-illuminated through the sclera.

A conspicuous feature in our cases was a shallow chamber, despite a perfectly closed wound. So a shallow chamber does not necessarily mean faulty healing. Therefore defective filling of the anterior chamber in the case of a well-closed wound, should be ascribed to something else. Our attention was particularly called to the fact, that in cases where the re-establishment of the chamber, due to an imperfect reunion of the lips of the incision, was retarded, though the eye remained soft, the choroid remained in its proper place. With one of our cases, two weeks after intra-capsular extraction, the chamber remained so shallow on account of the filtrating wound, that the bulging membrane of the vitreous body touched the cornea. Two months after operation the chamber'was still flat, and ocular pressure was $15 \mathrm{~mm}$. Hg. Nevertheless, the choroid remained in situ. Consequently the detachment cannot be ascribed to a leaking wound and subsequent hypotony, because then it should be present in every such case, and again a mal-united wound should characterize every detachment. Actual observation confirms the opposite : detachment is less probable, if the wound leaks outwardly. Nevertheless I do not believe that an outward filtrating wound necessarily excludes detachment.

As the table shows, most detachments occurred following the scleral flap incision. Since this operation differs from the others only by the form of the incision, the cause of detachment has to be sought for in this direction. Before incision within the limbus is finished, by means of Graefe's knife a $3 \mathrm{~mm}$. long and broad flap is cut out upwards through the half thickness of the sclera, as has been described already by Horváth (1939), the originator of this method. 
The anterior chamber is separated from the supra-choroidal space only by the trabecular tissue of the angle of the former, and the anterior end of the ciliary muscle attached to the corner of the chamber (see Fig.). The thickness of this part, its distance from



1 The sclera ; 2 cornea; 3 ciliary body : 4 iris ; 5 anterior chamber : 6 supra-choroidal space: 7-9 anterior end of the ciliary muscle, scleral spur and trabecular tissue of the angle of the anterior chamber (line of cleavage).

the limbus, and the thickness and ${ }_{1}$ curvature of the sclera vary in individuals, although only by small differences. On account of this it is rather difficult to cut a $3 \mathrm{~mm}$. flap off in such a manner that it should not contain the entire thickness of the sclera in the form of a central strip. By slicing the sclera, the separating part is easily cut, whereby a small cleft is formed between the anterior chamber and the supra-choroidal space so that both communicate. 
As soon as the wound closes, the accumulating aqueous does not . press the slightly bulging vitreous body back, and does not form the anterior chamber, but finding less resistance along the communicating intra-ocular way, leaks backward behind the choroid and lifts the latter from its base. The chamber, despite a well-joined incision, remains therefore shallow as long as the aqueous leaks backward. As soon as the incision closes, normalisation of intra-ocular pressure begins but is not completed so long as the continually produced aqueous is absorbed through the choroid, as well as by the physiological way. This explains the high-grade hypotony accompanying detachment. The anterior chamber fills up and the intra-ocular pressure rises as backward leakage decreases. As soon as lateral seepage becomes less than absorption, detachment decreases accordingly. As the aforesaid communication closes, the aqueous is progressively absorbed beneath the choroid, the choroid sinks back again, and the intra-ocular pressure is re-established.

In five of our cases the anterior chamber was re-established after operation, but emptied after a few days, despite perfect outward closure of the incision. This delayed intra-ocular abortion of the chamber may have been due to the part separating the two cavities having been only damaged by the incision, and not cut entirely; a certain pressure of the aqueous collecting after the wound being closed, is obviously necessary for penetration.

Detachment after intra-capsular extraction is much more frequent, if the attachment of the ciliary. body is disturbed by the incision (scleral and conjunctival flap). The traction of the zonular arch may complete the still imperfect communication. This rôle of the zonular arch becomes the more obvious, the more the incision is scleral (see table). Probably a forced traction of the strong zonular arch, together with a simultaneous loosening of attachment of the ciliary body, suffices to cause detachment. Loss of vitreous may sponsor detachment.

Accepting the aforesaid views, we may understand why, in the case of a badly united incision, despite the shallow chamber, no detachment occurs. An imperfectly closed wound does not promote, but rather inhibits detachment, because in the meantime, owing to aqueous loss, the angle of the chamber may close. In one case the detachment occurred 6 days after operation, despite the anterior chamber remaining shallow the whole time on account of an imperfectly united incision. Aqueous seeped without difficulty outwards, and leaked more thoroughly beneath the choroid only after the incision had closed. The choroidal vessels may rupture during operation if the patient's blood-pressure is high. The ensuing haemorrhage may detach the choroid. There were no signs of inflammation associated with the choroidal detachment and no 
evidence of any general medical disorder. The intra-ocular pressure before operation was normal. On the basis of these phenomena the author succeeded in inducing choroidal detachment experimentally in animals.

Prognosis of early post-operative detachment is good. The time of complete replacement of the choroid depends on the time elapsing since the complete closure of the angle and on the degree of detachment. It usually takes 1 to 2 weeks. Most authors agree that, if the replacement of the detachment is perfect, no serious consequences follow. I believe that hypotony following operation may even be advantageous for healing of the incision. Prognosis of detachment due to haemorrhage is less favourable. Verhoeff, Filatov, Averbach, and Vail succeeded in saving some sight by instantaneous scleral puncture following an expulsive haemorrhage.

Views on treatment vary. Müller recommends puncture to avoid functional disturbance. Elschnig also stated that a rapid cure followed puncture of choroidal detachment cases which had persisted for weeks after operation, but he recommended it only if the detachment was not due to haemorrhage, and the peripheral circulatory system was in perfect condition. Löhlein proposed cauterisation of fistula-forming wounds. Axenfeld proposed compresses. Imre was satisfied by the effect of pilocarpine. He believed that it caused hyperaemia and swelling of the ciliary body, which helped in the closure of the angle of the chamber.

I believe that detachment following glaucoma iridectomy originates in the same way as that following cataract operations. In our cases following trephine and cyclodialysis detachment also occurred repeatedly. In my experience, anti-glaucoma operations accompanied by detachment were alway's successful, the eye becoming hypotonic. In case of tissues becoming opaque by operative haemorrhage or pressure following glaucoma operation, examination for detachment is inhibited ; furthermore, it is hindered by the narrowness of the pupil, or peripheral position of the detachments. The opening of the filtration angle by cyclo-dialysis is violent and blunt, and any ensuing haemorrhage may soon obstruct the path of the aqueous. This circumstance may account for the comparative rarity of detachment following this operation.

Imre sometimes used scleral puncture by electro-cautery for glaucoma, and this was sometimes followed by choroid detachment. The cauterisation of the sclera softens the eye, and choroidal detachment is a post-operative complication. Closure of the wound increases the intra-ocular pressure. In this case no backward seepage of the aqueous can be assumed, as.the operation is remote from the filtration angle. Detachment in such cases is of different origin. It is not only promoted by decrease of intra-ocular pressure, 
seepage of the vitreous body, and its shrinkage, but the haemorrhage and transudate elicited by thermic effect elevate the choroid. In choroidal detachment caused by backward seepage of aqueous, as described above in connection with cataract and glaucoma operation, hypotony stops only after the choroid is replaced, whereas in the case of ignipuncture the intra-ocular pressure increases, despite the persistance of the detachment, even after the wound has closed.

\section{Summary}

The onset of choroidal detachment following cataract extraction is influenced by the type of incision, the method of traction and by the auxiliary manipulation applied. If during operation the suprachoroidal space is opened by the incision, a communication between the anterior chamber and the former is established. The aqueous oozes backward beneath the choroid, and raises it from its base. Therefore the chamber is shallow, despite the incision being closed towards the palpebral aperture. Hypotony of the detached eye is due to the constant absorption of the aqueous. As soon as the filtration angle is closed, the backward leakage of the aqueous stops, the chamber is re-established, the intra-ocular pressure becomes normal; the fluid from beneath the choroid becomes absorbed, slowly the choroid becomes replaced and no further damage is done. Similarly are explained detachment following anti-glaucomatous operations.

\section{LITERATURE}

Blaskovics, L. and KREIKER, A. (1938).-Eingriffe am Auge. (Stuttgart).

Bonnet, P. and GrandClement, E. (1939):-Arch. d'Ophtal:, 3. Csillag, F. (1939).-Szemészet.

(1940). - Klin. Monatsbl. f. Augenheilk., 105. (1948). - Szemészet tanulmányok.

Fronimopoulos, J. (1942).-Klin. Monatsbl. f. Augenheilk., 108.

Fuchs, E. (1902). -Graefes Arch.f. Ophthal., 53.

HAGEN (1921).-Klin. Monatsbl.f. Augenheilk., 66.

HORVÁTH, B. (1936).-Ibid., 96. (1939).-lbid. . 102.

LINDNER, J. (1936.)-Graefes Arch.f. Ophthal., 135.

MAYER, H. D. (1940)-Zentralbl. f. Ophthal,, 44.

MeEsman (1921).-Arch. Augenheilk., 90.

- (1943).-Rev. Bulgare d'Ophtal.

Meller, J. (1912).-Graefes Arch.f. Ophthal., 80.

O'BRIEN (1935).-Arch. Ophthal., 14.

PARKer, A. E. P. (1946). Brit. J. Ophthal., 30.

PURTSCHER, E. (1942).-Graefes Arch. f. Ophthal., 144.

Sмiтh, I. W. (1946).-Amer. J. Ophthal., 29.

URBANEK, J. (1941).-Klin. Monatsbl.f. Augenheilk., 106.

WEVE, H. (1941). -Ibid. 